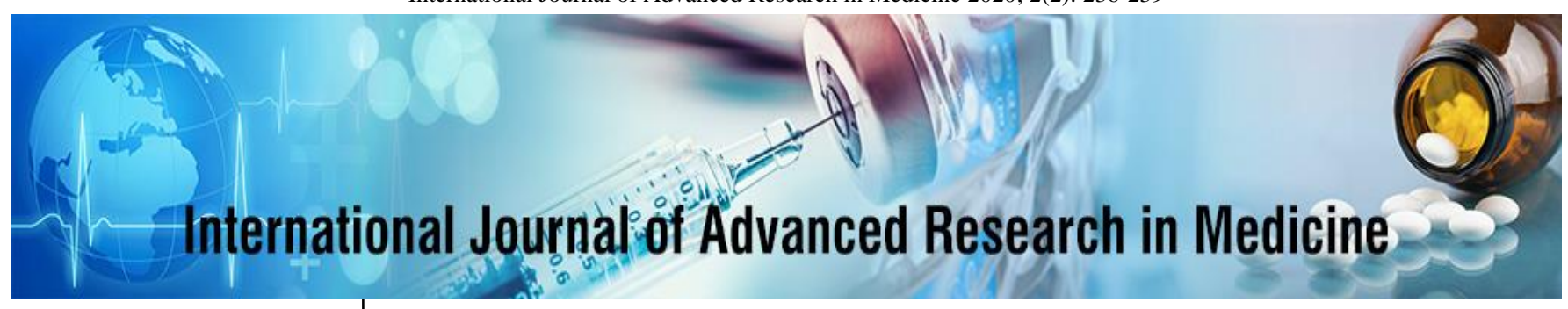

E-ISSN: 2706-9575

P-ISSN: 2706-9567

IJARM 2020; 2(2): 236-239

Received: 22-05-2020

Accepted: 25-07-2020

Dr. Akkamahadevi V Nipanal

Consulting Physician,

Department of General

Medicine, BMCRI, Bangalore,

Karnataka, India

Dr. Madhukumar MH

Consulting Physician,

Department of General

Medicine, BMCRI, Bangalore,

Karnataka, India

\section{Dr. Nagappah}

Professor, Department of

General Medicine, BMCRI,

Bangalore, Karnataka, India

Corresponding Author: Dr. Akkamahadevi V Nipanal Consulting Physician, Department of General Medicine, BMCRI, Bangalore, Karnataka, India

\section{Role of C-reactive protein in neuroinfection}

\author{
Dr. Akkamahadevi V Nipanal, Dr. Madhukumar MH and Dr. Nagappah
}

DOI: https://doi.org/10.22271/27069567.2020.v2.i2d.74

\begin{abstract}
CRP belongs to the pentraxin family of calcium dependent ligand-binding plasma proteins. The pentraxin family named for it electron micrographic appearance from the Greek penta (five), ragas (berras). CRP can be produced in neurons and lipopolysaccharides can induce CRP production in extrahepatic sites. Its production is controlled by interleukin- 6 and it binds to polysaccharides present in many bacteria, fungi and protozoal parasites. Meningitis patients admitted and willing to give consent in the medicine department at Victoria hospital and Bowring \& Lady Curzon hospital, BMCRI, Bangalore. The NPV was $100 \%$, which implied that bacterial meningitis could be ruled out if the CSFCRP was negative. The accuracy of CRP for bacterial meningitis was $100 \%$.
\end{abstract}

Keywords: C-reactive protein, neuroinfection, pentraxin

\section{Introduction}

The central nervous system (CNS) may appear protected from perturbations in the environment by a blood brain barrier - a system of tight junction around capillaries that resist the entry of pathogens, inflammatory cells and macromolecules into the subarachnoid space and the brain. However, the barrier fails to resist the intensity of the microbial world and its presence also cause difficulty in the delivery of antimicrobial agents in adequate concentrations ${ }^{[1]}$.

Bacterial meningitis is the most common form of suppurative CNS infection, with an annual incidence in the United States of $>2.5$ cases/100,000 population. The organisms most often responsible for community-acquired bacterial meningitis are Streptococcus pneumonia $(\sim 50 \%)$, Neisseria meningitidis ( 25\%), group B streptococci $(\sim 15 \%)$, and Listeria monocytogenes $(\sim 10 \%)$. Haemophilus influenza type $b$ accounts for $<10 \%$ of cases of bacterial meningitis in most series. N. meningitidis is the causative organism of recurring epidemics of meningitis every 8 to 12 years ${ }^{[2]}$.

A critical event in the pathogenesis of meningitis is the inflammatory reaction induced by the invading pathogen. Many of the neurologic manifestations and complications of meningitis result from the immune response to the invading pathogen rather than from direct bacteria induced tissue injury. As a result, neurologic injury can progress even after the CSF has been sterilized by antibiotic therapy ${ }^{[2]}$.

The prognosis of bacterial meningitis is critically dependent on a rapid causal diagnosis and implementation of prompt treatment. However, clinical and biochemical parameters available within the few hours that follow patients admission are not reliable enough, except when bacteria are to be found in the cerebrospinal fluid under the microscope. Today, Creactive protein (CRP) is the most widely used inflammatory marker in emergency departments with aim to discriminate bacterial from non-bacterial infections ${ }^{[3]}$.

\section{C-reactive protein}

Tillet and Francis, French investigators in 1930 described a substance that was present in the sera of acutely ill patients which was able to bind to the cell wall c-polysaccharide of streptococcus pneumoniae and agglutinate the organisms. In 1941, the substance was shown to be a protein and given the name C-reactive protein (CRP) ${ }^{[4]}$.

CRP belongs to the pentraxin family of calcium dependent ligand-binding plasma proteins. The pentraxin family named for it electron micrographic appearance from the Greek penta (five), ragas (berras) ${ }^{[5]}$.

CRP can be produced in neurons ${ }^{[6]}$ and lipopolysaccharides can induce CRP production in 
extrahepatic sites [7]. Its production is controlled by interleukin-6 and it binds to polysaccharides present in many bacteria, fungi and protozoal parasites ${ }^{[7]}$.

In view of such observations, the present study was conducted to find out the usefulness of CSF-CRP for the rapid diagnosis \& management of bacterial meningitis in adults.

\section{Methodology \\ Source of data}

Meningitis patients admitted and willing to give consent in the medicine department at Victoria hospital and Bowring \& Lady Curzon hospital, BMCRI, Bangalore.

\section{Method of collection of data}

This group included 50 Patients with clinical and CSF laboratory findings consistent with Bacterial meningitis.

\section{Clinical features}

- Acute onset of symptoms of meningitis - Triad of fever, headache, nuchal rigidity.

- Altered mental status.

- Nausea, vomiting and photophobia.

- Seizures.

- Signs of meningeal irritation. Can be associated with sinusitis, otitis media, and signs of meningeal irritation.

\section{CSF analysis showing}

- Pleocytosis of $>250$ cells $/ \mathrm{mm}^{3}$, predominantly neutrophils.

- Proteins $>50 \mathrm{mg} / \mathrm{dl}$.

- Sugar $<40 \mathrm{mg} / \mathrm{dl}$.

- Gram stains and culture positivity.

\section{Neuroimaging showing}

Evidence of diffuse meningeal enhancement, abscesses or parameningeal focus.

\section{Inclusion criteria}

1. Age $>18$ years.

2. Clinical features suggestive of meningitis

\section{Exclusion criteria}

1. Age $<18$ years.

2. Patients in whom lumbar puncture is contraindicated.

3. Associated severe hepatic dysfunction.

4. A patient with acute infections at sites other than central nervous system.

5. Patients on steroid.

An estimation of CSF C-Reactive protein level was done for all the patients satisfying the inclusion and exclusion criteria.

\section{Study design}

A prospective clinical evaluation study is undertaken to study the predictive value of CSF CRP in relation to Bacterial meningitis.

\section{Statistical methods}

Student $\mathrm{t}$ test (two tailed, independent) has been used to find the significance of study parameters on continuous scale between two groups (Inter group analysis) on metric parameters. Leven1s test for homogeneity of variance has been performed to assess the homogeneity of variance.

Descriptive and inferential statistical analysis has been carried out in the present study. Results on continuous measurements are presented in Mean SD (Min-Max) and results on categorical measurements are presented in Number (\%). Significance is assessed at 5\% level of significance.

\section{Significant figures}

+ Suggestive significance $(P$ value: $0.05<P<0.10)$

* Moderately significant $(P$ value: $0.01<P<0.05)$

** Strongly significant $(P$ value: $P<0.01)$

\section{Statistical software}

The Statistical software namely SAS 9.2, SPSS 15.0, MedCalc 9.0.1, Systat 12.0 and R environment ver.2.11.1 were used for the analysis of the data and Microsoft word and Excel have been used to generate graphs, tables etc.

\section{Results}

Table 1: Age distribution of patients

\begin{tabular}{|c|c|c|}
\hline Age (Years) & Number of patients & In percentage (\%) \\
\hline $18-20$ & 04 & 8 \\
\hline $21-40$ & 12 & 24 \\
\hline $41-60$ & 29 & 58 \\
\hline$>60$ & 05 & 10 \\
\hline Total & 50 & 100 \\
\hline
\end{tabular}

The mean age of the 50 patients studied was $39.86+14.58$ years. $58 \%(\mathrm{n}=29)$ of patients in the study were aged between 41-60 years.

Table 2: Gender distribution of meningitis

\begin{tabular}{|c|c|c|}
\hline Gender & Bacterial meningitis & Percentage (\%) \\
\hline Male & 31 & $62 \%$ \\
\hline Female & 19 & $38 \%$ \\
\hline Total & 50 & 100 \\
\hline
\end{tabular}

In this study, $62 \%$ were Male and $38 \%$ were Female.

Table 3: Levels of CSF-CRP

\begin{tabular}{|c|c|c|}
\hline Type of meningitis & Total number of patients & $\begin{array}{c}\text { CRP }(\mathbf{m g} / \mathbf{d l}) \\
\text { Mean value } \pm \text { SD }\end{array}$ \\
\hline Bacterial meningitis & 50 & $23.16 \pm 5.56$ \\
\hline
\end{tabular}

The mean CSF-CRP level in Bacterial meningitis, was $23.16 \pm 5.56 \mathrm{mg} / \mathrm{dl}$.

Table 4: $P$ value of CSF-CRP in bacterial meningitis

\begin{tabular}{|c|c|c|c|c|}
\hline $\begin{array}{c}\text { Type of } \\
\text { meningitis }\end{array}$ & $\begin{array}{c}\text { Total number } \\
\text { of patients }\end{array}$ & \multicolumn{3}{|c|}{ CSF-CRP level (>5mg/dl) } \\
\cline { 3 - 5 } & Number & Percentage (\%) & P Value \\
\hline $\begin{array}{c}\text { Bacterial } \\
\text { meningitis }\end{array}$ & 50 & 50 & 100 & $\begin{array}{c}P<0.001 \\
* *\end{array}$ \\
\hline
\end{tabular}

The result is statistically significant with a $P$ value $<0.001$. 
Table 5: Diagnostic performance of CSF-CRP

\begin{tabular}{|c|c|c|c|c|c|c|}
\hline Type of meningitis & Total number & Sensitivity & Specificity & PPV & NPV & Accuracy \\
\hline Bacterial meningitis & 50 & $99 \%$ & $100 \%$ & $99 \%$ & $100 \%$ & $100 \%$ \\
\hline
\end{tabular}

The NPV was $100 \%$, which implied that bacterial meningitis could be ruled out if the CSF-CRP was negative. The accuracy of CRP for bacterial meningitis was $100 \%$.

\section{Discussion}

The epidemiology of bacterial meningitis has changed significantly in recent years reflecting a dramatic decline in the incidence of meningitis due to Haemophilus influenzae, and a smaller decline in that due to Neisseria meningitides, following the introduction and increasingly widespread use of vaccines for both these organisms ${ }^{[1]}$.

Table 6: Cerebrospinal fluid (CSF) abnormalities in bacterial meningitis ${ }^{[2]}$

\begin{tabular}{|l|l|}
\hline Opening pressure & $>180 \mathrm{mmH}_{2} \mathrm{O}$ \\
\hline White blood cells & $10-10,000 /$ microLit; neutrophils predominate \\
\hline Red blood cells & Absent in nontraumatic tap \\
\hline Glucose & $<2.2 \mathrm{mmol} / \mathrm{L}(<40 \mathrm{mg} / \mathrm{dl})$ \\
\hline CSF/Serum glucose & $<0.4$ \\
\hline Protein & $>0.45 \mathrm{~g} / \mathrm{L}(>45 \mathrm{mg} / \mathrm{dl})$ \\
\hline Gram's stain & Positive in $>60 \%$ \\
\hline Culture & Positive in $>80 \%$ \\
\hline Latex agglutination & $\begin{array}{l}\text { May be positive in patients with meningitis due to Streptococcus pneumonia, Neisseria meningitidis, } \\
\text { Heamophilus influenzae type b, Escherichia coli, Group B streptococci }\end{array}$ \\
\hline Limulus lysate & Positive in cases of gram-negative meningitis \\
\hline PCR & Detects bacterial DNA \\
\hline
\end{tabular}

Abbreviation: $\mathrm{PCR}-$ polymerase chain reaction

\section{Pathophysiology ${ }^{[2]}$}

The most common bacteria that cause meningitis, $S$. pneumoniae and $N$. meningitidis, initially colonize the nasopharynx by attaching to nasopharyngeal epithelial cells. Bacteria are transported across epithelial cells in membranebound vacuoles to the intravascular space or invade the intravascular space by creating separations in the apical tight junctions of columnar epithelial cells. Once in the bloodstream, bacteria are able to avoid phagocytosis by neutrophils and classic complement-mediated bactericidal activity because of the presence of a polysaccharide capsule. Bloodborne bacteria can reach the intraventricular choroid plexus, directly infect choroid plexus epithelial cells, and gain access to the CSF. Some bacteria, such as $S$. pneumoniae, can adhere to cerebral capillary endothelial cells and subsequently migrate through or between these cells to reach the CSF. Bacteria are able to multiply rapidly within CSF because of the absence of effective host immune defenses. Normal CSF contains few white blood cells (WBCs) and relatively small amounts of complement proteins and immunoglobulins. The paucity of the latter two prevents effective opsonization of bacteria, an essential prerequisite for bacterial phagocytosis by neutrophils. Phagocytosis of bacteria is further impaired by the fluid nature of CSF, which is less conducive to phagocytosis than a solid tissue substrate.

A critical event in the pathogenesis of meningitis is the inflammatory reaction induced by the invading pathogen. Many of the neurologic manifestations and complications of meningitis result from the immune response to the invading pathogen rather than from direct bacteria induced tissue injury. As a result, neurologic injury can progress even after the CSF has been sterilized by antibiotic therapy ${ }^{[2]}$.

Raised ICP is an expected complication of bacterial meningitis and the major cause of obtundation and coma in this disease. More than $90 \%$ of patients will have a CSF opening pressure $>180 \mathrm{mmH} 2 \mathrm{O}$, and $20 \%$ have opening pressures $>400 \mathrm{mmH} 2 \mathrm{O}$. Signs of increased ICP include a deteriorating or reduced level of consciousness, papilledema, dilated poorly reactive pupils, sixth nerve palsies, decerebrate posturing, and the Cushing reflex (bradycardia, hypertension, and irregular respirations) ${ }^{[2]}$.

The most disastrous complication of increased ICP is cerebral herniation. The incidence of herniation in patients with bacterial meningitis has been reported to occur in as few as $1 \%$ to as many as $8 \%$ of cases ${ }^{[2]}$.

The rash of meningococcemia begins as a diffuse erythematous maculopapular rash resembling a viral exanthem, but the skin lesions of meningococcemia rapidly become petechial. Petechiae are found on the trunk and lower extremities, in the mucous membranes and conjunctiva, and occasionally on the palms and soles ${ }^{[2]}$.

This increase in CRP level might be due to entry of CRP into CSF by passive diffusion across the highly inflamed meninges or de-novo synthesis in central nervous system ${ }^{[8]}$. Present study was consistent with the findings of various studies.

In a study conducted by Vaishnavi $\mathrm{C}$ et al, CRP in CSF was significantly higher in patients with pyogenic meningitis compared to tubercular meningitis. Authors concluded that the estimation of CRP in the differential diagnosis of meningitis might be made to give a preliminary diagnosis of meningitis ${ }^{[9]}$.

Riberio MH et al estimated the levels of CRP in CSF from 33 patients with bacterial meningitis, 21 patients with lymphocytic meningitis and 54 controls. $100 \%$ of these patients with bacterial meningitis were correctly classified on the basis of measurement of CRP levels in CSF. In conclusion authors recommend the estimation of CRP in $\mathrm{CSF}$ in the differentiation of bacterial from non-bacterial meningitis ${ }^{[10]}$.

Hemavani $\mathrm{V}$ et al evaluated the role of CRP in CSF in differentiation of meningitis. The study included 499 CSF samples from cases of viral, pyogenic, tuberculous and fungal meningitis and 580 normal CSF samples. CRP positive by qualitative latex agglutination test was seen in 
$73.3 \%$ of CSF samples from partially treated pyogenic meningitis and $92 \%$ among pyogenic meningitis cases. All suspected cases of tuberculosis meningitis were negative for CRP in the CSF while only 1 out of CSF samples for bacteriologically confirmed tuberculous meningitis was positive. CRP was raised in $27.2 \%$ and $12.5 \%$ of CSF samples from candidal and cryptococcal meningitis cases respectively, while none of the 102 samples from suspected viral meningitis and 580 non-meningitis cases were positive for CRP in the CSF. The study concludes that CSF CRP determination can be of value to differentiate pyogenic versus other microbial meningitis etiology. However, it cannot differentiate between tuberculosis, fungal and viral meningitis ${ }^{[13]}$.

A meta-analysis by Gerdes LU et al suggested that a negative CRP test in either CSF or serum can be used with a very high probability to rule out bacterial meningitis ${ }^{[11,12]}$.

\section{Conclusion}

Study concludes that use of CSF C-Reactive Protein can be used for early diagnosis of Bacterial meningitis. This is necessary when gold standard test for meningitis like Smear and/or culture for bacteria, is not available or negative or time consuming.

CSF-CRP levels were higher in Bacterial meningitis.

\section{References}

1. Verma A, Solbrig MV. Neurology in Clinical Practice. 4th ed. Joseph Jankovic; Elsevier 2004, P1473.

2. Karen Roos L, Kenneth Tyler L. Harrison's Principles of Internal Medicine. $19^{\text {th }}$ ed. New York: McGraw Hill 2015;164:883-906.

3. Smith E. C-reactive protein in the emergency department. Emer Med J 2006;23:241-243.

4. Rifai N, Warnick Teitz RG. Textbook of Clinical Chemistry \& Molecular Diagnostics. $4^{\text {th }}$ ed: Butterworth Heinemann 1999, P962-963.

5. Young DS, Bermes EW, Harerstick Teitz DM. Textbook of Clinical Chemistry and Molecular Diagnostics, $4^{\text {th }}$ ed, Butterworth Heinemann 1999, P555.

6. Yasojima Schwabc K. Human neurons generate Creactive protein and amyloid P. Brain Res 2000;887:8089.

7. Intorna M, Alles VV. Cloning of mouse ptx3, a new member of the pentraxin gene family expressed at extrahepatic sites. Blood 1996;87:1862-72.

8. Corrall CJ, Pepple JM, Moxon ER, Huges WT. Creactive protein in the spinal fluid of children with meningitis. J Pediatr 1981;99:365-369.

9. Vaishnavi C, Dhand UK, Dhand R, Agnihotri N, Ganguly NK. C-reactive proteins, immunoglobulin profile and mycobacterial antigens in cerebrospinal fluid of patients with pyogenic and non tuberculous meningitis 1992;36(3):317-325.

10. Ribeiro MA, Kimura RT, Irulegui. Cerebrospinal fluid levels of lysozyme, IgM and C-reactive protein in the identification of bacterial meningitis. J Trop Med Hyg 1992;95(2):87-94.

11. Sutinen J, Sombrero L, Paladin FJ. Etiology of central nervous system infections in the Philippines and the role of serum C-reactive protein in excluding acute bacterial meningitis. Int J Infect Dis 1998;3(2):88-93.

12. Gerdes LU, Jorgensen PE, Nexo E, Wang P. C-reactive protein and bacterial meningitis: A meta-analysis. Scand J Clin Lab Invest 1998;58(5):383-93.

13. Hemavani N, Chitnis D, Joshi SP. C-reactive protein in $\mathrm{CSF}$ and its role in differential diagnosis of meningitis. Ind J Med Microb 2001;19(1):26-29. 